\title{
The ergonomics analysis of work: a case study in a experimental farm
}

\author{
Maria de Lourdes Santiago Luz ${ }^{\mathrm{a},}$, Syntia Lemos ${ }^{\mathrm{a}}$ \\ ${ }^{a}$ Departament of Industrial Engineering, State University of Maringá, Av. Colombo, 5790, Bloco 19/20, Maringá - \\ PR, Brazil
}

\begin{abstract}
This work presents the initial steps of ergonomic analysis of industrial activities, which are being held in the premises of an Agricultural Experimental farm belonging to an institution of higher education. The methods employed in the initial step was confined to desk research, its purpose was to know the demographic profile and understand organizational structure followed by systematic observations in workplaces using semi-structured interviews and a questionnaire of perception to operators. The presentation of the results will provide a summary of the analysis of activity sectors visited, understanding the biomechanical efforts entered (posture and strength), as well as the evaluation according to the perception of officials to respect the constraints, ambience and suggestions. It was noted that $90 \%$ of employees surveyed feel some kind of discomfort. It also highlights the age factor of this questionnaire, in which the majority (90\%) is above 40 years old, and this fact confirms and reinforces the appearance or accumulation of injuries among the employers. At this stage there was no intention to deploy improvements, but create assumptions and guide future intervention actions that can be performed.
\end{abstract}

Keywords: Ergonomic Analysis of Work, Experimental farm, Agricultural

\section{Introduction}

Ergonomic job analysis assumes that the ergonomist, before the activity analysis, look for ways to identify the requirements and constraints in which the undertaking is, and the representations that have guided the decisions in the corresponding sectors dealing with demand [1]. The authors point out that the analysis methods of Labor Act, therefore, in addition to the methods of analysis of the activity, methods of operation of the company's operation and the identification of requirements and constraints under which they are actors.

Therefore, this work purports to present the initial steps of ergonomic analysis of industrial activities, which are being held in the premises of an Agricultural Experimental farm belonging to an institution of higher education [3]. The activities carried out in Experimental Farm have as main goal to generate knowledge with teaching and research in the areas of agriculture and zootechnics. The ergonomic study is restricted to understanding and analysis of the envi- ronment surrounding the task, with a focus on operators, who work in the care, management and animal experiments, linked to the area of animal science. The presentation of the results will provide a summary of the analysis of activity sectors visited, Understanding the biomechanical efforts entered (posture and strength), as well as the evaluation according to the perception of officials to respect the constraints, ambience and suggestions. The work at the farm is characterized for being a rural, dispersed work and has a great diversity of operations. Usually its activities are not constant and in most cases there isn't an execution order set. Operations are performed according to the necessity of the experiment, and there are cases in which the management and control activities are performed daily by varying the short, medium and long term according to the creation or research. It is also characterized for being a work of the unstructured type, and it does not have a job set, requiring constant displacements during the execution of activities.

*E-mail: mlsluz@uem.br. 


\section{Methodology}

The research was conducted with the consent of employees, supervisors and directors of the Experimental Farm, including the collaboration of all parties involved, helping decisively so that the initial survey could occur in a participatory manner. The methods applied in the initial phase was limited to desk research in order to meet the demographic profile and understand the organizational structure followed by systematic observations in the workplace, and semi-structured interviews using a questionnaire of perception with the operators. The questionnaire of perception occurred in some sectors of animal husbandry: cattle, laying hens, breeding of broilers, quail breeding, goat rearing, comprising a total of 10 employees.

\section{Results and analysis}

The results summarized in this paper stratify and reflect the determinants that will guide the rest of the research. It was found that all employees perform overtime of the working day. This is because they need to work on weekends and holidays, performing rotation of activities in those days. There is a perception of some kind of constraint, $90 \%$ of employees surveyed feel some discomfort.

The results presented by both the questionnaire and through observation identify the activity of transporting food, the most uncomfortable, with demonstration of $53 \%$ of respondents. This is because the workers perform the operations of handling and transportation of food bags manually. The activity of cleaning the shed was also considered among the most tiring and heavy, with $24 \%$ of respondents. The Figure 1 illustrates the percentage of workers and all the activities indicated by them that are developed during the workers routine, and causes some uncomfort and constraints.

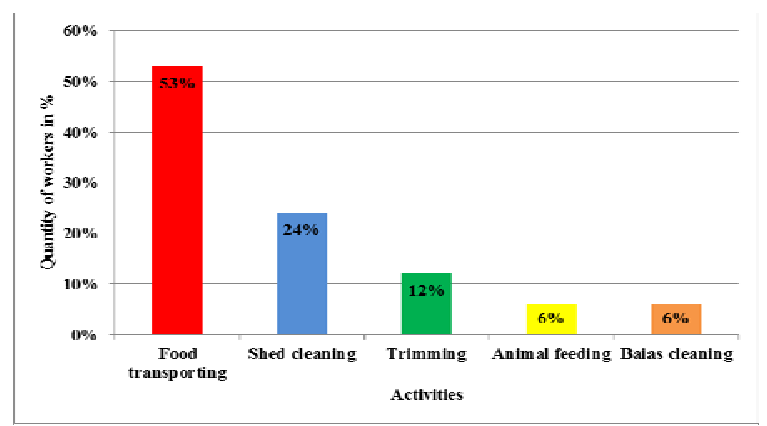

Figure 1: Duties that cause constraints
The Figure 2 illustrates some jobs that are part of the routine in the cattle department, such as milking and cleaning.

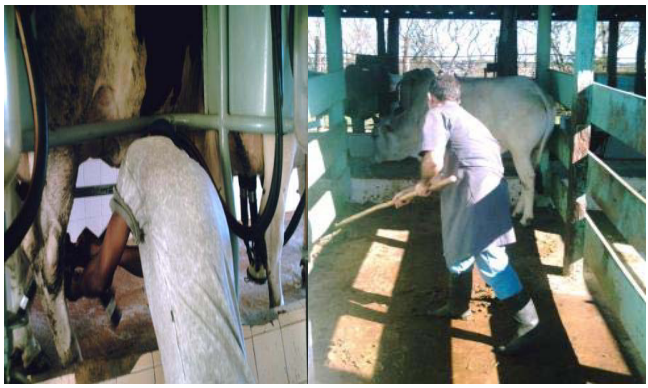

Figure 2: Activity of milking and cleaning

The age factor was also evidenced in this questionnaire, in which the majority $(90 \%)$ is above 40 years old, and this fact supports and enhances the appearance or accumulation of injuries among workers. The Figure 3 highlights that only $9 \%$ of the workers are less than 30 years old. This information was obtained by documental analysis totalizing 60 employees sited at the Farm.

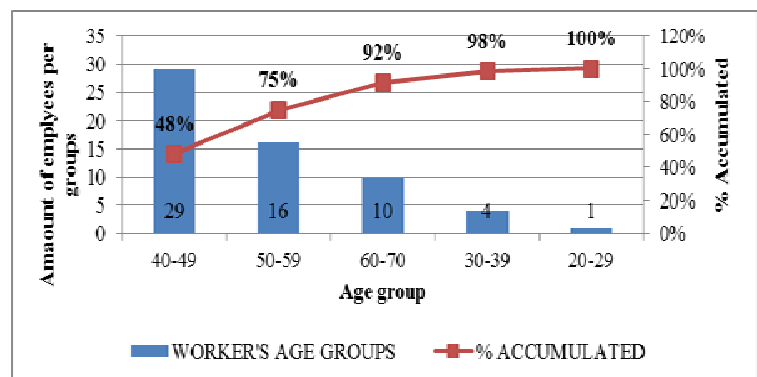

Figure 3: Graphic of age rating

Regarding the area of discomfort in the body, operators stressed the lower region of the spine, and left shoulder was the second most cited. The Figure 4 illustrates some of the workers movements during their routine [2].

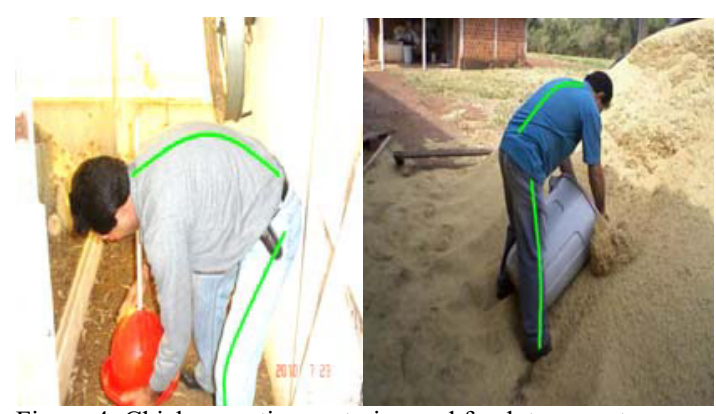

Figure 4: Chicken section-watering and food transport 


\section{Discussion}

The approach presented in this article was limited to early stages of research, where there were different types of constraints validated with the results of the questionnaire of perception and semi-structured interviews. At this stage there was no intention to implement improvements, but to create assumptions and guide future intervention activities that can be performed. Regarding ergonomic research at the Experimental Farm, it is characterized as the study of rural labor, but having as a product, the operating mode of the operators and responses to surveys. It is evident that a knowledge-generating organization, whose specific nature, presents few studies in this area. Most work is in rural activities related to the design of equipment or agricultural activities [4]. However, there are few studies on the activities of work in animal breeding and management, which are led to the operational ways and the activity analysis of the worker.

\section{References}

[1] F. Daniellou and P. Béguin, Metodologia da ação ergonômica: abordagens do trabalho real, in: Ergonomia, P. Falzon, ed., Blucher, São Paulo, 2007, pp. 281-301.

[2] G. K. Takatsuji. Análise Ergonômica do Trabalho no setor de avicultura: estudo de caso na Fazenda Experimental de Iguatemi (FEI).Trabalho de Conclusão de Curso de Engenharia de Produção, Universidade Estadual de Maringá, 2010.

[3] M. L.S. Luz et al. Qualidade de Vida no Trabalho sob a abordagem de estudos ergonômicos: projeto piloto na Fazenda Experimental de Iguatemi. Disponível em: www.sgp.uem.br: 8080/sgp/índex.html

[4] S. F. B. Gemma, Complexidade e agricultura: organização e análise ergonômica do trabalho na agricultura orgânica. Tese. Doutorado, Faculdade de Engenharia Agrícola, Campinas, 2008. 